\title{
Microbial and "de novo" transformation of dicarboxylic acids by three airborne fungi
}

\author{
Valérie Côté, Gregor Kos, Roya Mortazavi, Parisa A. Ariya
}

\begin{abstract}
Micro-organisms and organic compounds of biogenic or anthropogenic origins are important constituents of atmospheric aerosols, which are involved in atmospheric processes and climate change. In order to investigate the role of fungi and their metabolisation activity, we collected airborne fungi using a biosampler in an urban location of Montreal, Quebec, Canada ( $\left.45^{\circ} 28^{\prime} \mathrm{N}, 73^{\circ} 45^{\prime} \mathrm{E}\right)$. After isolation on Sabouraud dextrose agar, we exposed isolated colonies to dicarboxylic acids $\left(\mathrm{C}_{2}-\mathrm{C}_{7}\right)$, a major group of organic aerosols and monitored their growth. Depending on the acid, total fungi numbers varied from 35 (oxalic acid) to $180 \mathrm{CFU} / \mathrm{mL}$ (glutaric acid). Transformation kinetics of malonic acid, presumably the most abundant dicarboxylic acid, at concentrations of 0.25 and $1.00 \mathrm{mM}$ for isolated airborne fungi belonging to the genera Aspergillus, Penicillium, Eupenicillium, and Thysanophora with the fastest transformation rate are presented. The initial concentration was halved within 4.5 and 11.4 days. Other collected fungi did not show a significant degradation and the malonic acid concentration remained unchanged $(0.25$ and $1.00 \mathrm{mM}$ ) within 20 days. Degradation of acid with formation of metabolites was followed using high performance liquid chromatography-ultraviolet detection (HPLC/UV) and gas chromatography-mass spectrometry (GC/MS), as well as monitoring of ${ }^{13} \mathrm{C}$ labelled malonic acid degradation with solid-state nuclear magnetic resonance spectroscopy (NMR). Using GC/MS we identified two processes driving chemical modifications of organic aerosol solutions: (I) formation of metabolites within several days, and (II) rapid release ( $\leq 2 \mathrm{~min})$ of organic molecules from fungal species upon the insertion of taxa in organic aerosol solutions. Metabolites included aromatic compounds and alcohols (e.g. trimethylbenzene and butanol). Potential atmospheric implications of our results are discussed.
\end{abstract}

\section{Introduction}

Airborne particles suspended in air, aerosols, are recognized as important players in climatic processes, as they interact with the solar and terrestrial irradiation by absorption and scattering processes (IPCC, 2007, See et al., 2006). Aerosols also lead to the formation of cloud droplets and ice crystals by serving as cloud condensation nuclei $(\mathrm{CCN})$ and ice forming nuclei (IN). Among these, organic compound aerosol represents a significant proportion (31-33 mass-\% over continental Europe) of the total atmospheric aerosols (Seinfeld and Pandis, 1998).

Monocarboxylic and dicarboxylic acids (DCA) are the major identified organic compounds found in urban, remote continental and marine atmospheric aerosols (Narukawa et al., 2002, Sun and Ariya, 2006) and among them small molecular weight, oxalic, malonic and succinic acids are the most abundant identified DCA (Kawamura and Ikushima, 1993), formed from biomass burning, fuel combustion and oxidation products of aromatic hydrocarbons and alkanes (Wang et al., 2002).

Bioaerosols are a group of organic aerosols that are airborne particles or molecules, alive or dead, originating from biological activity (Hirst, 1995). They can serve as IN and CCN, and are also suggested as being able to alter the chemical composition of other organic IN and $\mathrm{CCN}$, hence contributing to atmospheric processes (Vali et al., 1976, Ariya et al., 2002, Ariya and Amyot, 2004). The flux of bioaerosols from plants and soils entering the atmosphere is recognized as originating from two types of vegetation zones: (a) high primary production row crop area, and (b) relatively low-production desert area. The highest measured flux was $1.95 \times 10^{6}$ colony forming units (CFU) $\mathrm{m}^{-2} \mathrm{~h}^{-1}$ for the crop area and $1.7 \times 10^{3} \mathrm{CFU} \mathrm{m}^{-2} \mathrm{~h}^{-1}$ for a desert (Lighthart and Sharffer, 1994).

Atmospheric conditions such as high relative humidity, wind velocity, and temperature are among the factors that determine the number density of airborne taxa originating from terrestrial sources such as plants leaves, and crops, and also the extent of entire intact airborne cells that can exist in the atmosphere (Rosas et al., 1993). Up to 25\% of the insoluble part of aerosols is suggested to be biological particles (Morris et al., 2004). They originate mostly from plants and soil, however several oceanic sources have also been observed (Lindemann et al., 1982, Lindemann and Upper, 1985). Hence, many of the identified bioaerosols in atmosphere also exist in several other parts of the Earth's ecosystem. Bioaerosols can be formed from entire biological organisms such as bacteria, 
This document is the unedited Author's version of a Submitted Work that was subsequently accepted for publication in 'Environmental Science \& Technology', copyright (c) American Chemical Society after peer review. To access the final edited and published work https://www.sciencedirect.com/science/article/pii/S0048969707010972 doi: 10.1016/j.scitotenv.2007.10.035

fungi, yeasts, viruses, plant and animal fragments or by particles originating from them including cell debris (Fuzzi et al., 1997, Wang et al., 2002, Ariya and Amyot, 2004, Morris et al., 2004). The general capability of microorganisms to metabolise organic compounds has long been established and is also exploited in industrial processes e.g. for the production of organic acids (Yeoman, 1965, Salim and Singh, 1988, Wentworth and Cooper, 1996). It is less widely known that micro-biological activity has also been reported in the atmosphere and active bacteria, fungi and yeasts were observed in fogs, cloud droplets, and snow samples: Sattler et al. (2001) have collected bacteria from cloud droplets and demonstrated that they are reproducing at temperatures around $0{ }^{\circ} \mathrm{C}$. They suggested that cloud water is a microbial habitat. Fuzzi et al. (1997) have also observed viable bacteria in fog droplets and suggested that these act as culture media for airborne biological particles. Other articles also deal with the presence of viable micro-organisms in the atmosphere and connected environmental compartments ( Ariya et al., 2002, Schadt et al., 2003). Interestingly, the presence of bacteria has been detected in the boundary layer, in the upper troposphere, and even in the stratosphere at altitudes up to $41 \mathrm{~km}$ above the sea surface (Wainwright et al., 2003). Certain bacteria, such as Pseudomonas syringae, are capable of effectively catalyzing the freezing of supercooled water in atmosphere at temperatures as high as $-1{ }^{\circ} \mathrm{C}$, placing it among the best-known IN (Vali et al., 1976). Cultivable bacteria and fungi represented 0.01 to $0.9 \%$ of total organic compounds collected in clouds, water, snow rain, and aerosol samples (Bauer et al., 2002). Sugars, organic acids and amino acids in fogs, snow and clouds droplets have been suggested as nutrients for microbial activity (Morris et al., 2004).

The purpose of this study was to examine the effect of bioaerosols on atmospheric chemistry. Selected isolated airborne fungi collected from urban environment were used to evaluate: (I) the timescale of micro-biological transformation of liquid organic acid solutions (major constituents of organic aerosol), (II) the chemical changes due to micro-biological degradation, and/or changes resulting from contact of organic acids from non-biological origin with airborne taxa, and (III) microbial transformations (including a possible change in their efficacy to act as IN or $\mathrm{CCN}$ ) and identification of metabolites produced "de novo". Their potential role as bioaerosols in atmospheric chemistry will be herein discussed.

\section{Materials and methods}

Air samples from an urban area in Montreal ( $45^{\circ} 28^{\prime} \mathrm{N}, 73^{\circ} 45^{\prime} \mathrm{E}$, Quebec, Canada) were collected for airborne fungi isolation. The samples used in this study were taken in 16 October 2002 using a commercial biosampler set-up (SKC 225-9594). The sampler was made of glass and consisting of an inlet, three tangential sonic nozzles that maintain a constant flow rate of $4.2 \mathrm{~L} / \mathrm{min}$ each, resulting in a total flow of approximately $12.5 \mathrm{~L} / \mathrm{min}$. According to the specifications of the manufacturer, sampling efficiency is near $100 \%$ down to a particle size of $0.5 \mu \mathrm{m}$, when the efficiency drops to $90 \%$ (SKC) and the nozzle design reduces particle bounce and re-aerosolization. The outside temperature during sampling was between $7.7{ }^{\circ} \mathrm{C}$ and $11{ }^{\circ} \mathrm{C}$. Relative humidity was between $65 \%$ and $85 \%$ and wind was blowing with $17 \mathrm{~km} / \mathrm{h}$ to $35 \mathrm{~km} / \mathrm{h}$ from the east. Cloud cover was complete with rain between 14:00 and 16:00 $\mathrm{h}$ EST. Air masses reaching the sampling site originated from the Atlantic coast in southern Maine $72 \mathrm{~h}$ prior to sampling. Trajectory calculations were carried out using the NOAA Hysplit model (Draxler and Rolph, 2007). Mineral oil (SKC ViaTrap) was used as to trap the sample in the collection vessel to keep micro-organisms viable. Air was sampled during $6.5 \mathrm{~h}$ with a membrane pump (SKC) for a total of $4875 \mathrm{~L}$ samples air. Tubing was made of Teflon (Sigma) with stainless steel fittings (Swagelok). Airborne fungi were isolated from mineral oil on Sabouraud dextrose agar (SDA, Becton \& Dickinson) doped with DCA (one of the following: oxalic, malonic, succinic, adipic, glutaric and pimelic acid, Sigma) and incubated at $20^{\circ} \mathrm{C}$ for 5 days. Isolated fungal species represent common airborne fungi that we had previously observed in Montreal and classified with a light microscope by their optical properties. The total number of fungi was counted using a light microscope (MicroscOptics SL500). A graphic illustration of all procedures is provided in the Appendix, Fig. A1.

\subsection{Malonic acid degradation experiments}

Each isolated colony was transferred to a sterilized aqueous solution that contained malonic acid $(0.25 \mathrm{mM}$ or $1 \mathrm{mM}$ ). The choice of malonic acid concentration was based on the LOD of the HPLC-UV system employed in this study in order to allow for a reliable investigation of decreasing malonic acid concentration. At regular intervals a 25-mL sample was withdrawn and centrifuged (at 13,000 $\times g$ for $15 \mathrm{~min}$ at $0{ }^{\circ} \mathrm{C}$ ) to remove cells. The concentration of acid in solution was periodically measured with an HPLC (HP 1100, Hewlett Packard) equipped with an Eclipse XDB-C18 column $(150 \times 4.6 \mathrm{~mm}$, Agilent $)$ and a UV detector at a wavelength of $220 \mathrm{~nm}$. A mixture of $45 \%$ HPLC grade methanol (Fisher) and 55\% ultrapure water (Millipore) was used as mobile phase with a flow rate of $1 \mathrm{~mL} / \mathrm{min}$ resulting in a system pressure of $79.29 \mathrm{MPa}(115 \mathrm{psi})$. A volume of $20 \mu \mathrm{L}$ of each DCA solution was injected and 
This document is the unedited Author's version of a Submitted Work that was subsequently accepted for publication in 'Environmental Science \& Technology', copyright (c) American Chemical Society after peer review. To access the final edited and published work https://www.sciencedirect.com/science/article/pii/S0048969707010972 doi: 10.1016/j.scitotenv.2007.10.035

previously filtered $(0.2 \mu \mathrm{m}$, Pall Acrodisc) to avoid contamination of the HPLC system with micro-organisms. All pH measurements were carried out with a buffer-calibrated glass electrode (Fisher).

\subsection{Product studies}

The metabolisation products were analysed by gas chromatography with mass-spectrometric detection (HP 6890/5973, Hewlett Packard, GC/MS) and by ${ }^{13} \mathrm{C}$ high-resolution solid-state NMR (Varian Infinity CMX-300). Organic compounds from fungal solutions before and after the transformation of the initial DCA were extracted and derivatized with (Bis-trimethylsilyl)-trifluoro-acetamide (BSTFA, Sigma) (Plewka et al., 2003). An aliquot of $5 \mathrm{~mL}$ sample volume was mixed with $1 \mathrm{~mL}$ of $50 \%$ (v/v) sulfuric acid (Fisher) and after the addition of $4 \mathrm{~g}$ sodium chloride (Fisher) and $5 \mathrm{~mL}$ of ethyl acetate (Sigma) the solution was mixed 30 times by inversion. After phase separation the upper phase was dried with sodium-sulfate for $20 \mathrm{~min} ; 240 \mu \mathrm{L}$ of extract were then mixed with $60 \mu \mathrm{L}$ BSTFA and derivatives were formed by incubation at $70{ }^{\circ} \mathrm{C}$ for $20 \mathrm{~min}$. A volume of $1 \mu \mathrm{L}$ of the derivative was injected in the GC/MS, which was equipped with a HP5-MS column (cross-linked 5\%-phenylmethyl-siloxane, $30 \mathrm{~m} \times 0.25 \mathrm{~mm} \times 0.25 \mu \mathrm{m}$, Hewlett Packard). Injection was carried out in splitless mode with a total flow of $48.7 \mathrm{~mL} / \mathrm{min}$. The purge vent was opened after $1.40 \mathrm{~min}$ with a flow of $44.7 \mathrm{~mL} / \mathrm{min}$. The injector temperature was $250{ }^{\circ} \mathrm{C}$. The oven temperature was increased from an initial 50 to $250{ }^{\circ} \mathrm{C}$ at a rate of $5{ }^{\circ} \mathrm{C} / \mathrm{min}$ during the product separation. Holding time for the final temperature was $5 \mathrm{~min}$. Detection was performed scanning a mass range from 10 to $550 \mathrm{amu}$ after a solvent delay of $1.40 \mathrm{~min}$. Detected compounds were identified using the NIST MS Library 2.1 (NIST, Gaithersburg, MD) and by comparison with standard spectra. Structural similarity was assessed with the "match" and "reverse match" parameters and the overall probability measure of the database program.

The solutions used for the ${ }^{13} \mathrm{C}$ solid-state NMR were prepared as described in the previous section except that we used ${ }^{13} \mathrm{C}$ malonic acid $\left(\mathrm{C}_{2}\right.$ atom labelled, Sigma). Samples for solid-state NMR were freeze-dried by evaporation of water using a home-built vacuum line system and cooling with liquid nitrogen before analysis.

The morphology of the fungi was identified using a light microscope. A sample from the fungi solutions was fixed on a microscope slide, stained with TB Brilliant Green K (BD Biosciences) and then observed.

The polymerase chain reaction (PCR) technique was used to amplify the $18 \mathrm{~S}$ ribosomal deoxyribo-nucleic acid (rDNA) sequence of each fungus for the identification of fungi. As a first step rDNA was extracted by mixing fungi that were cultivated for $24 \mathrm{~h}$ on SDA plates with $1 \mathrm{~mL}$ of $100 \times$ lysis buffer $(50 \mathrm{mM}$ Tris- $\mathrm{HCl}, 50 \mathrm{mM}$ ethylenediaminetetraacetic acid (EDTA) adjusted to $\mathrm{pH} 8$ with sodiumhydroxide, $2 \%$ sodiumdodecylsulfate (SDS), $1 \%$ Triton) and $350 \mathrm{mg}$ of autoclaved glass beads. All solutions were sterilized either by autoclaving (Napco) or filtering $(0.2 \mu \mathrm{m}$; Pall). The mixture was homogenized for $5 \mathrm{~min}$ (optimized for the investigated fungal species) at maximum speed with a Genie Disruptor (Scientific Industries). $20 \mu \mathrm{L}$ of RNase (10 mg/mL, EMD Biosciences) were added and the mixture incubated at $37^{\circ} \mathrm{C}$ for $1 \mathrm{~h}$. After two centrifugation steps (for 2 min at 13,000 rpm) with a phenol-chloroform-isoamylalcohol mixture (Fisher), rDNA was precipitated from the supernatant with 3 M sodium acetate (Sigma) at pH 5.2 and cold, anhydrous ethanol (Fisher). The mixture was stored for complete precipitation at $-20{ }^{\circ} \mathrm{C}$ overnight and then centrifuged for $15 \mathrm{~min}$ at 13,000 rpm in a microcentrifuge (Thermo Centra CL13). The precipitate was washed with cold ethanol, dried on a vacuum line and re-suspended in $100 \mu \mathrm{L}$ ultrapure water (Millipore).

For electrophoresis an agarose gel (Sigma, $1.5 \mathrm{~g} / 150 \mathrm{~mL}$ with TAE buffer) was prepared and the sample loaded with $2.5 \mu \mathrm{L}$ TAE buffer after mixing it with $10 \mu \mathrm{L}$ of sample. Runtime was 90 min at $140 \mathrm{~V}$. The gel was stained with ethidiumbromide solution (Sigma) for $30 \mathrm{~min}$ and washed with ultrapure water for 20 min. rDNA was visualized with ultraviolet light.

The rDNA sample was thawed on ice and reactants were centrifuged before use. PCR solutions were prepared with $5 \mu \mathrm{L} 10 \times$ TAQ polymerase buffer (Promega), $50 \mathrm{mM}$ magnesiumchloride and $1 \mu \mathrm{L}$ of $10 \mathrm{mM} \mathrm{dNTP}$ (Promega). Panfungal primers, ITS1 (5'-TCC GTA GGT GAA CCT GCG G-3'), and ITS 4 (5'-TCC TCC GCT TAT TGA TAT GC-3') (both Integrated DNA Technologies, USA), were used for amplification of ITS region of fungi (White et al., 2002). PCR was performed with a sample volume of $40 \mu \mathrm{L}$ per vial in a GeneAmp thermal cycler (Applied Biosystems) with an initial denaturation step at $94{ }^{\circ} \mathrm{C}$ for 4 min followed by 30 cycles of denaturation at $94{ }^{\circ} \mathrm{C}$ for $30 \mathrm{~s}$, primers annealing at $56^{\circ} \mathrm{C}$ for $20 \mathrm{~s}$, and primers extension at $72{ }^{\circ} \mathrm{C}$ for $30 \mathrm{~s}$. Cycling was terminated by a final extension step at $72{ }^{\circ} \mathrm{C}$ for $10 \mathrm{~min}$. The cycle sequencing of the amplicons was carried out using a Taq DNA polymerase (Applied Biosystems, $5 \mathrm{U} / \mu \mathrm{L}, 0.25 \mu \mathrm{L}$ ) and D-rhodamine dye terminators (Applied Biosystems). The samples were re-suspended in a solution of formamide-blue dextran-EDTA (Sigma), denaturized, and 
This document is the unedited Author's version of a Submitted Work that was subsequently accepted for publication in 'Environmental Science \& Technology', copyright (c) American Chemical Society after peer review. To access the final edited and published work https://www.sciencedirect.com/science/article/pii/S0048969707010972 doi: 10.1016/j.scitotenv.2007.10.035

electrophoresed on an ABI Prism 377 DNA sequencer (AME Bioscience). The species were determined by comparing the $100 \%$ similarity of $18 \mathrm{~S}$ sequences with the one contained in the GenBank database (National Center for Biotechnology Information, Bethesda, Maryland).

\section{Results}

In the following section, we will report on (I) isolation and identification of selected airborne fungi collected in the city of Montreal including the determination of growth of isolated fungi on solid plate with DCA, (II) chemical degradation of DCA solutions by fungi, and, finally, (III) detailed product studies.

(I) A total of 18 different fungi were isolated from air samples collected in Montreal. Fig. 1 shows the number of fungi collected with the biosampler set-up and isolated on SDA plates doped with the most abundant $\mathrm{DCA}\left(\mathrm{C}_{2}-\mathrm{C}_{7}\right)$ found in the atmosphere. The total number of fungi ranged between 120 and $180 \mathrm{CFU} / \mathrm{mL}\left(492.3\right.$ to $\left.738.4 \mathrm{CFU} / \mathrm{m}^{3}\right)$, with the exception of the collection plates that contained oxalic acid, where an abundance of approximately $30 \mathrm{CFU} / \mathrm{mL}\left(123.1 \mathrm{CFU} / \mathrm{m}^{3}\right)$ was observed. The growth on the control, which was SDA and sample without acids added only showed a similar number of colony forming units, indicating that oxalic acid greatly reduces, but other investigated acids do not inhibit fungal growth.

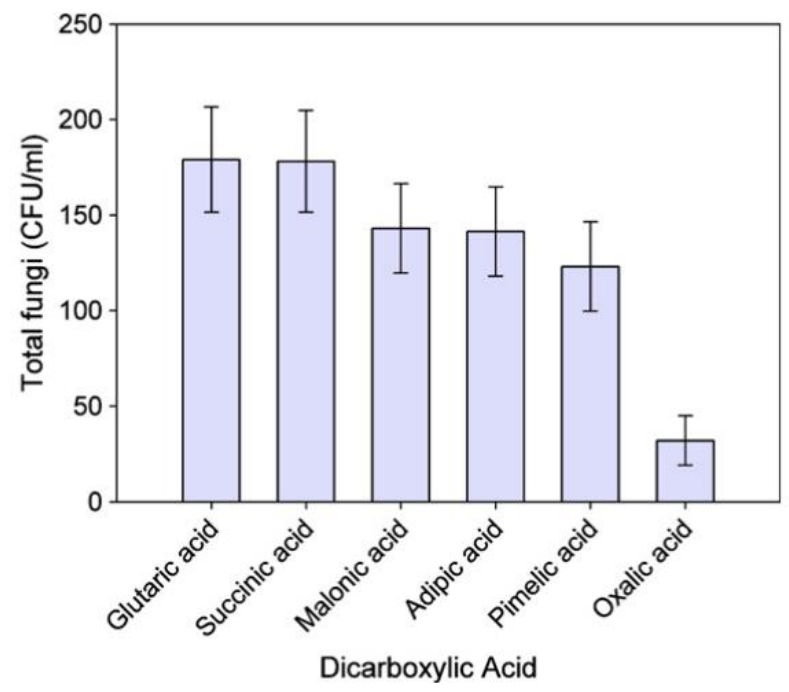

Fig. 1 - Total fungi number isolated on SDA containing different DCA. Error bars were calculated using the Poisson distribution with a confidence limit of $99 \%$.

(II) We performed degradation experiments with oxalic, succinic and adipic acids, and observed degradation of these DCA in presence of the airborne taxa; however the transformation processes occurred at much slower rates (data not shown). We hence focus in the next sections on experiments with malonic acid. It is the second-most abundant DCA in the atmosphere and therefore highly relevant for atmospheric processes. Oxalic acid, which is even more abundant, inhibits growth due to a significant $\mathrm{pH}$ change with increasing concentration ( $\underline{\text { Fig. } 1)}$. We detected 18 types of fungi from air samples that were capable of transforming malonic acid concentrations of 0.25 and $1.00 \mathrm{mM}$. The concentration of all blank malonic acid solutions (containing no fungal species) remained unchanged.

For isolate \#1, the three top hits were highly associated with Eupenicillium javanicum and Penicillium expansum species: E. javanicum $\underline{\mathrm{DQ} 401106}$, P. expansum $\mathrm{DQ401105}$, and P. expansum DQ266450. The second isolate (isolate \#2) was highly associated with Penicillium chrysogenum, and Thysanophora longispora species, and the four top hits were $P$. chrysogenum AF548087, P. chrysogenum M55628, T. longispora AB075440, and T. longispora $\mathrm{AB} 069700$. For the third isolate (isolate \#3), the four top hits were highly associated with Eurotium berbariourum, Aspergillus fumigatus, Aspergillus tamari, and Aspergillus glaucus species: Eurotium herbariorum AF548072, A. fumigatus AF548063, Aspergillus oryzae AP007173, A. tamari AF516140, and A. glaucus AY083218 (for sequences see the Appendix Fig. A2). According to Fig. 2a, the time required to decrease the initial concentration by half was approximately 4.5 days for isolates \#1 and \#3 and 11.5 days for isolate \#2, the 
fastest of the originally 18 isolated species. Fig. $2 \mathrm{~b}$ shows the effect of change of concentration and thus the $\mathrm{pH}$ on malonic acid transformation rate by isolate \#1, and an enhanced transformation time of 7 days at a concentration of $1.00 \mathrm{mM}$ and 5.5 days at $0.25 \mathrm{mM}$. A higher concentration of malonic acid changes the $\mathrm{pH}$ of the solution from 7.0 $(0.25 \mathrm{mM})$ to $5.0(1 \mathrm{mM})$, which in turn changes the efficiency of fungi to metabolise malonic acid. The $\mathrm{pH}$ at lower concentrations was closer to the optimum for maximum turnover for these species (Bassi and Margaritis, 1996).
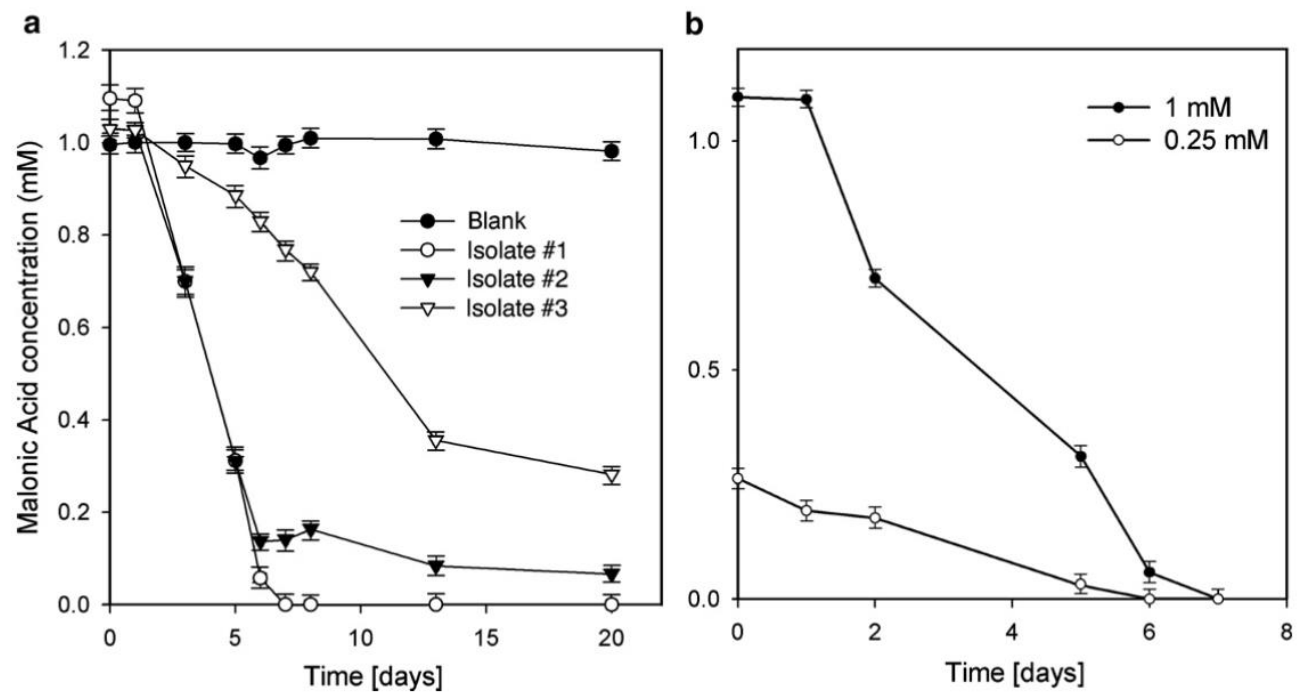

Fig. 2 - (a) Transformation of malonic acid ( $1 \mathrm{mM}$ ) by isolate \#1, isolate \#2 and isolate \#3 and (b) at a concentration of $0.25 \mathrm{mM}$ (pH 7.0) and $1 \mathrm{mM}$ (pH 5.0) by isolate \#1 (error bars represent $3 \mathrm{~s}$ ).

(III) Product studies were two-fold: The first thrust focused on the formation of degradation products after conversion of malonic acid by fungi monitored over a period of several days. The second thrust focused on a very short time scale $(\leq 2 \mathrm{~min})$ after introduction of a single isolated fungal colony into a malonic acid solution and filtering through $0.2 \mu \mathrm{m}$ filters. This was done in order to detect compounds that did not directly originate from metabolic processes, but can readily be released from micro-organisms (e.g. because they could be weakly attached to fungal membranes and/or contained in other parts of the fungus).

HPLC analysis revealed the presence of several new compounds in solutions, after the complete conversion of malonic acid by isolated fungal colonies (data not shown). To provide identification of chemical species, fungal metabolites and the organic compounds released from their structure were identified using GC/MS (Table 1, Table 2). Solid-state NMR provided further evidence of the turnover of labelled malonic acid by fungi (Fig. 3). A number of compounds identified by GC/MS after complete transformation of malonic acids are different from these identified right after the insertion of fungi. The latter solution contains a large number of alcohols, which are not detected in the sample, where malonic acid is transformed by fungi, which indicates that the rapidly released alcohols could serve as additional nutrients for the micro-biological transformation. Compounds such as ketones, alcohols and aromatics listed in Table 1 were found in solutions after the complete transformation of malonic acid after several days of incubation. Table 2 presents the chemicals released within $2 \mathrm{~min}$ after the introduction of micro-organisms to the malonic acid solution, originating from fungi. Sterilized malonic acid solutions were used as blanks and did not show the formation of compounds over time (or release from e.g. contaminated glassware). Due to analytical instrumental limitations and structural complexity of samples, several peaks in MS spectra remained unidentified. Additionally, many potential macromolecules with molecular weights $>500$ amu could not be detected reliably by the GC/MS set-up (single quadrupole mass filter) used in this study. This is also true for GC/MS studies for ${ }^{13} \mathrm{C}$-labelled malonic acid, as other studies conducted in our lab did not reveal the presence of ${ }^{13} \mathrm{C}$-containing metabolites. This could be due either to the high complexity of the biochemical mixture and/or the incorporation of the labelled C-atom in larger molecules (e.g. proteins) that are not accessible by the quadrupole MS. There is no doubt, however, about malonic acid driving the conversion process, as it was the only source of carbon present in solutions. 
This document is the unedited Author's version of a Submitted Work that was subsequently accepted for publication in 'Environmental Science \& Technology', copyright (c) American Chemical Society after peer review. To access the final edited and published work https://www.sciencedirect.com/science/article/pii/S0048969707010972 doi: 10.1016/j.scitotenv.2007.10.035

\begin{tabular}{|c|c|c|c|}
\hline Name & $\begin{array}{l}\text { Molecular } \\
\text { weight }\end{array}$ & Structure & Isolate(s) \\
\hline 3-Methylhexane & 100.20 & & Isolate \#3 \\
\hline Formic acid-hydrazide & 60.06 & U & Isolate \#2 \\
\hline 3,4-Dimethylbenzamide & 149.19 & & $\begin{array}{l}\text { Isolate \#1 } \\
\text { Isolate \#3 }\end{array}$ \\
\hline 2-Methoxyethanol & 76.09 & & $\begin{array}{l}\text { Isolate \#1 } \\
\text { Isolate \#2 } \\
\text { Isolate \#3 }\end{array}$ \\
\hline 1,2-Dimethylbenzene & 106.17 & & $\begin{array}{l}\text { Isolate \#1 } \\
\text { Isolate \#2 } \\
\text { Isolate \#3 }\end{array}$ \\
\hline $\begin{array}{l}\text { 4-Hydroxy-4- } \\
\text { methylpentan-2-one }\end{array}$ & 116.16 & & Isolate \#2 \\
\hline Isopropylpropionate & 116.16 & & Isolate \#3 \\
\hline 1,2-Ethanediol & 62.07 & & Isolate \#3 \\
\hline
\end{tabular}

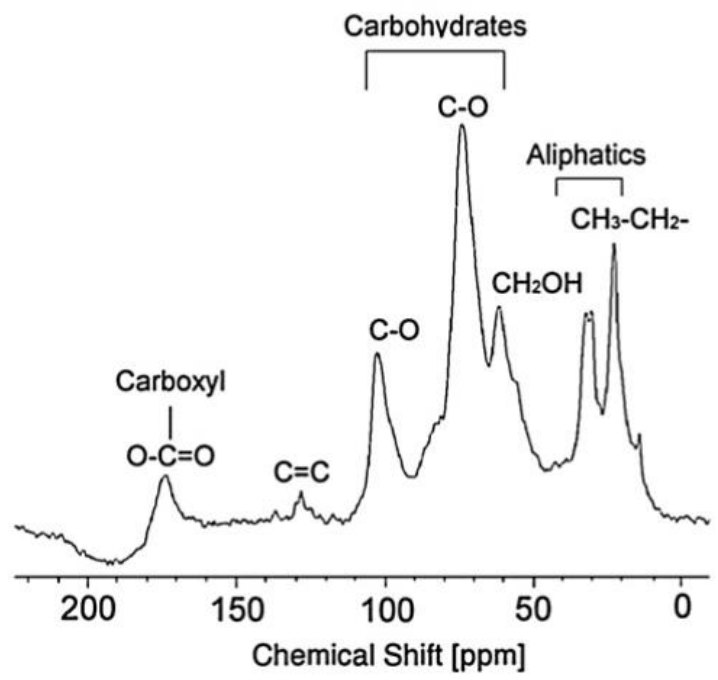

Fig. 3 - Solid-state NMR spectrum after a complete transformation of ${ }^{13} \mathrm{C}$ malonic acid by isolate \#1. 


\begin{tabular}{|c|c|c|c|}
\hline Name & Molecular weight & Structure & Isolate(s) \\
\hline Isobutylacetate & 116.16 & & $\begin{array}{l}\text { Isolate \#1 } \\
\text { Isolate \#2 }\end{array}$ \\
\hline Ethanol & 46.07 & & $\begin{array}{l}\text { Isolate \#3 } \\
\text { Isolate \#1 } \\
\text { Isolate \#2 }\end{array}$ \\
\hline & & & Isolate \#3 \\
\hline 1-Butanol & 74.12 & & $\begin{array}{l}\text { Isolate \#2 } \\
\text { Isolate \#3 }\end{array}$ \\
\hline 1,2,3-Trimethylbenzene & 120.19 & & $\begin{array}{l}\text { Isolate \#1 } \\
\text { Isolate \#2 }\end{array}$ \\
\hline 1,2-Ethanediol & 62.07 & & $\begin{array}{l}\text { Isolate \#3 } \\
\text { Isolate \#1 } \\
\text { Isolate \#2 }\end{array}$ \\
\hline 1-Decanol & 158.28 & & $\begin{array}{l}\text { Isolate \#3 } \\
\text { Isolate \#1 } \\
\text { Isolate \#3 }\end{array}$ \\
\hline 2-Decanol & 158.28 & & $\begin{array}{l}\text { Isolate \#1 } \\
\text { Isolate \#2 }\end{array}$ \\
\hline Di-(-2ethylhexyl)-adipate & 370.57 & & $\begin{array}{l}\text { Isolate \#3 } \\
\text { Isolate \#1 } \\
\text { Isolate \#2 } \\
\text { Isolate \#3 }\end{array}$ \\
\hline (1-Methylethyl)-cyclohexane & 126.24 & & $\begin{array}{l}\text { Isolate \#1 } \\
\text { Isolate \#2 } \\
\text { Isolate \#3 }\end{array}$ \\
\hline 1,3- and 1,4-Dimethylbenzene & 106.17 & & $\begin{array}{l}\text { Isolate \#1 } \\
\text { Isolate \#2 } \\
\text { Isolate \#3 }\end{array}$ \\
\hline
\end{tabular}

\section{Discussion}

From a total of 18 fungi sampled from urban air in Montreal, QC, three isolates were capable of fast and efficient micro-biological degradation of malonic acid solutions and were identified as belonging to the genera: Aspergillus, Penicillium, Eupenicillium, Eurotium and Thysanophora. Several previous studies have shown their high concentrations in the atmosphere at several urban, suburban and remote locations ( Mohr, 2000, Durand et al., 2002, Wu et al., 2002, Gugnani, 2003, Moubasher et al., 1990, Stix, 1977). Our study has illustrated that growth of these airborne fungi is not inhibited by the presence of glutaric, succinic, malonic, adipic and pimelic acid. An exception is oxalic acid, which, due to its acidity, causes a decline of the $\mathrm{pH}$ of the solution and greatly inhibits (but not stops) fungal growth. The formation of metabolites after incubation with ${ }^{13} \mathrm{C}$-labelled malonic acid solution was confirmed by solid-state ${ }^{13} \mathrm{C}$ NMR spectroscopy. The uptake of malonic acid in turn drives chemical degradation of these organic molecules that are major constituents of atmospheric organic aerosols. The growth of taxa and chemical transformation rates vary as function of malonic acid concentration, the resulting $\mathrm{pH}$ of solution, and the type of the taxa. The three fungi isolates transformed malonic acid efficiently and hence we anticipate a range of transformation times depending on the conditions in a complex atmospheric environment. Additionally, previous results had indicated that reactions rates can be enhanced in a consortium containing fungi and bacteria (Ariya et al., 2002). It is therefore conceivable that airborne micro-organisms are active in environments favourable for microbial growth such as fogs, clouds, in/on biofilms, where organic aerosols are also present (Sun and Ariya, 2006). As a result, growth of micro-organisms and metabolism of organics could influence atmospheric processes. IN and CCN activity can be altered by several factors such as (a) increasing number of fungi, (b) their spatial distribution, as well as (c) the formation and transformation of organic products, together (d) with the a decrease of educts. For instance, it has been reported that malonic acid is not a good IN (Parsons et al., 2004) and its metabolisation could lead to increased activity due to IN promoting products. Other factors that could lead to enhanced growth and metabolisation are long-range transport (Prospero et al., 2005) to areas, with favourable meteorological conditions and reversible or irreversible deposition to matrices, which favour growth and metabolisation (e.g. snow and soil). Bacteria and fungi are especially suitable for these mechanisms, because of their ability to become dormant without loosing their viability once conditions again enable growth. Furthermore, many identified fungal metabolites and organic compounds have also a significant impact on human health already at low concentrations, including negative respiratory, gastrointestinal and narcotic effects, skin and eye irritants and cancers (Boutin-Forzano et al., 
This document is the unedited Author's version of a Submitted Work that was subsequently accepted for publication in 'Environmental Science \& Technology', copyright (c) American Chemical Society after peer review. To access the final edited and published work https://www.sciencedirect.com/science/article/pii/S0048969707010972 doi: 10.1016/j.scitotenv.2007.10.035

2006). This could have a local effect on the population urban areas, where heavy pollution is a problem and provides a good "substrate" for micro-organisms, e.g. during extended periods of fog and during other conditions that favour growth and activity of bacteria and fungi (Di Giorgio et al., 1996, Fuzzi et al., 1997).

We performed ${ }^{13} \mathrm{C}$ solid-state NMR measurements with doped solutions after the initial amount of ${ }^{13} \mathrm{C}$ malonic acid was completely consumed by the fungi to identify the functional groups of metabolites formed via the malonic acid metabolic pathway. It is noteworthy that solid-state NMR provides a powerful technique for identification of the chemical constituents that cannot be obtained merely by liquid NMR, due to the advantages of signal enhancement intrinsic to solid-state technique (Blumich, 1994). Sample preparation by freeze-drying also pre-concentrates metabolites, helping to overcome disadvantages of the relatively insensitive NMR technique. Preparation for liquid state NMR is easier, but requires large amounts of labelled malonic acid in order to be able to observe any metabolites that are formed. Furthermore, there is no limitation with regard to mass for NMR studies, so that also large molecules can be probed. The metabolites can readily be distinguished using solid state, which is not necessarily the case with the liquid state NMR commonly employed in micro-biological studies. Fig. 3 shows the incorporation of ${ }^{13} \mathrm{C}$ atoms by fungi isolate \#1 into several chemical environments, of which the only source was the labelled malonic acid. Similar data were obtained for fungi isolate \#2 and fungi isolate \#3. Peaks detected at chemical shifts of $174 \mathrm{ppm}$ (indicating carboxyl groups), 103, 74 and $63 \mathrm{ppm}$ (indicating carbohydrates) and several peaks in the 0 to $50 \mathrm{ppm}$ range (indicating aliphatic carbon atoms) reveal a variety of new species present in the in the spectra. A peak corresponding to labelled methanol was also identified in all spectra (peak at $50 \mathrm{ppm}$ ). Moreover, a peak at $43 \mathrm{ppm}$ reveals the presence of labelled amino acids on the fungi isolate \#2 spectrum. We observed that organic compounds are released from fungi after a short contact $(\leq 2 \mathrm{~min})$ with the aqueous DCA solutions, although the detailed mechanisms for such organic release require further research. It is thus conceivable that the composition of organic (acid) solutions that are a major identified component of organic aerosols can be altered in the presence or contact with entire or parts of airborne taxa, without waiting for metabolic activity to start, which usually takes overnight incubation. Moreover, micro-biological degradation of selected organic compounds could occur within a time scale of a few days, which is short enough for atmospheric transport of these organic aerosols to occur (Nepotchatykh and Ariya, 2002). Hence, one should not neglect the effect of micro-biological degradation, along with contact-induced chemical changes, when considering chemical and physical reactions of aerosols in atmosphere. Chemical transformation of species can even be further enhanced by consortia of airborne taxa in addition to individual organisms. Clouds and fogs provide a medium rich in water and nutrients (Fuzzi et al., 1997), enhancing the growth of airborne taxa and their potential micro-biological changes of organic aerosols. It is also important to note that since the chemical changes of organic solutions in presence of taxa appear to occur within a very short time scales (i.e. minutes), one should consider the potential of chemical changes by the remnants of airborne biological entities (e.g. cell debris), and therefore life or lack thereof is not necessarily the major issue, if several compounds are readily released from cell membranes and other cell components. As a result, it can be noted that chemical changes can alter the ability of organic aerosols to act as a good CCN or IN, hence altering the optical properties of aerosols and clouds, and therefore having an impact on climatic processes. This study confirms that the chemical changes due to either contact or metabolites may potentially change atmospheric chemistry. However, the significance of these reactions should be studied further. Gas phase reactions simulating atmospheric conditions and investigation of IN and CCN activity of model species are currently under way in our laboratory.

\section{Acknowledgments}

This work was supported by NSERC, Environment Canada, CFI and McGill University. We are grateful to Ali Khamessan from Actilab Inc. for fungal rDNA characterization, Fred Morin for NMR analysis, Josiane Lafleur for technical assistance, and Jackie Johnstone for proofreading the manuscript.

\section{Appendix A.}

Supplementary dataSupplementary data associated with this article can be found,in the online version, atdoi:10.1016/j.scitotenv.2007.10.035.

\section{References}


This document is the unedited Author's version of a Submitted Work that was subsequently accepted for publication in 'Environmental Science \& Technology', copyright (C) American Chemical Society after peer review. To access the final edited and published work https://www.sciencedirect.com/science/article/pii/S0048969707010972 doi: 10.1016/j.scitotenv.2007.10.035

Ariya PA, Nepotchatykh O, Ignatova O, Amyot M. Microbiologicaldegradation of atmospheric organic compounds. Geophys ResLett 2002;29:14

Bassi AS, Margaritis A. Cell growth kinetics and ice nucleationactivity ofPseudomonas syringae. Can J Chem Eng1996;74:301-7.

Bauer H, Kasper-Giebl A, Loflund M, Giebl H, Zibuschka R,Puxbaum H. The contribution of bacteria and fungal spores tothe organic carbon content of cloud water, precipitation andaerosols. Atmos Res 2002;64:109-19.

Blumich B. Solid-State NMR III: Organic matter. In: Diehl P, Fluck E,Gunter H, Kosfeld R, Seelig J, editors. NMR: Basic principles andprogress; 1994. p. 210 pp.

Boutin-Forzano S, Charpin-Kadouch C, Gouitaa A, Dumon H,Charpin D. Indoor air pollution: the importance ofidentifying disease-causing moulds. Rev Fr Allergol2006;46:197-203.

Di Giorgio C, Krempff A, Guiraud H, Binder P, Tiret C, Dumenil G.Atmospheric pollution by airborne microorganisms in the cityof Marseilles. Atmos Environ 1996;30:155-60.

Draxler R, Rolph G. HYSPLIT (Hybrid Single-particle LagrangianIntegrated Trajectory Model); 2007.http://www.arl.noaa.gov/ready/hysplit4.html;accessed July 27.

Durand KTH, Muilenberg ML, Burge HA, Seixas NS. Effect ofsampling time on the culturability of airborne fungi andbacteria sampled by filtration. Ann Occup Hyg 2002;46:113-8.

Fuzzi S, Mandrioli P, Perfetto A. Fog droplets—an atmosphericsource of secondary biological aerosol particles. Atmos Environ1997;31:287-90. Gugnani HC. Ecology and taxonomy of pathogenicAspergilli. FrontBiosci 2003;1:346-57.

Hirst JM. Bioaerosols: introduction, retrospect and prospect. In:Cox CS, Wathes CM, editors. Bioaerosols Handbook, vol. 5. BocaRaton: CRC Press; 1995. p. 621 pp.

IPCC. Changes in atmospheric constituents and in radiative forcing,fourth assessment report of the intergovernmental panel on climate change, contribution of the WG I; 2007. p. 153-71. ch 2.

Kawamura K, Ikushima K. Seasonal changes in the distribution ofdicarboxylic acids in the urban atmosphere. Environ SciTechnol $1993 ; 104: 3501-9$.

Lighthart B, Sharffer BT. Bacterial flux from chaparral into theatmosphere in the mid-summer at a high desert location.Atmos Environ 1994;28:1267-74.

Lindemann J, Upper CD. Aerial dispersal of epiphytic bacteria overbean plants. Appl Environ Microbiol 1985;50:1229-32.

Lindemann J, Constantinidiou HA, Barchet WR, Upper CD. Plantsas sources of airborne bacteria, including ice nucleation-activebacteria. Appl Environ Microb 1982;44:1059-63.

Mohr AJ. Fate and transport of microorganisms in air. In: Hurst CJ,Knudsen GR, McInerney MJ, Stetzenbach LD, Walter MV,Knudsen GR, editors. Manual of Environmental Microbiology,vol. 641. Washington: ASM Press; 2000. p. 1138 pp.

Morris CE, Georgakopoulos DG, Sands DC. Ice nucleation activebacteria and their potential role in precipitation. J Phys IV Fr2004;121:87-103.

Moubasher AH, Abdel-Hafez SI, Shoreit AA, Ismail MA.Keratinophilic and other fungi isolated from combineharvester wheat and sorghum dusts and from the atmosphereof winnow sites in Egypt. Folia Microbiol 1990;35:298-310.

Narukawa M, Kawamura K, Li SM, Bottenheim JW. Dicarboxylicacids in the Artic aerosols and snowpacks collected duringALERT 2000. Atmos Environ 2002;36:2491-9.

Nepotchatykh O, Ariya PA. Degradation of dicarboxylic acids (C2-C9)upon liquid-phase reactions with O3and its atmosphericimplications. Environ Sci Technol 2002;36:3265-9.

Parsons MT, Mak J, Lipetz SR, Bertram AK. Deliquescence of malonic, succinic, glutaric, and adipic acid particles. J GeophysRes-Atmos 2004;109:D6, D06212

Plewka A, Hofmann D, Muller K, Herrmann H. Determination of biogenic organic compounds in airborne particles by solventextraction, derivatisation and mass spectrometric detection.Chromatogr 2003;57:S253-9 Suppl. S.

Prospero JM, Blades E, Mathison G, Naidu R. Interhemispherictransport of viable fungi and bacteria from Africa to theCaribbean with soil dust. Aerobiol 2005;21:1-19. 
This document is the unedited Author's version of a Submitted Work that was subsequently accepted for publication in 'Environmental Science \& Technology', copyright (C) American Chemical Society after peer review. To access the final edited and published work https://www.sciencedirect.com/science/article/pii/S0048969707010972 doi: 10.1016/j.scitotenv.2007.10.035

Rosas I, Calderon C, Ulloa M, Lacey J. Abundance of airbornePenicilliumCFU in relation to urbanisation in Mexico City. Appl EnvironMicrobiol 1993;59:2648-52.

Salim M, Singh PN. Chemical composition of dormant spores ofAspergillus niger. P Natl A Sci India, B 1988;58:21-117.

Sattler B, Puxbaum H, Psenner R. Bacterial growth in supercooledcloud droplets. Geophys Res Lett 2001;28:239-42.

Schadt CW, Martin AP, Lipson DA, Schmidt SK. Seasonal dynamicsof previously unknown fungal lineages in tundra soils. Science2003;301:1359-61.

See SW, Balasubramanian R, Wang W. A study of the physical,chemical, and optical properties of ambient aerosol particles inSoutheast Asia during hazy and nonhazy days. J GeophysRes-Atmos 2006;111 D10, D10S08.

Seinfeld JH, Pandis SN. Atmospheric chemistry and physics. FromAir Pollution to Climate Change, vol. 97. New York: John Wileyand Sons; 1998. $1326 \mathrm{pp}$.

Stix E. Fungal spore content of the air in Munich. MMW MunchMed Wochenschr 1977;21:79-82 119.

Sun J, Ariya PA. Atmospheric organic and bio-aerosols as cloudcondensation nuclei (CCN): a review. Atmos Env2006;40:795-820.

Vali G, Christensen M, Fresh RW, Galyan EL, Maki LR, Schnell C.Biogenic ice nuclei. Part II: bacterial sources. J Atmos Sci1976;33:1565-70.

Wainwright M, Wickramasinghe NC, Narlikar JV, Rajaratnam P.Microorganisms cultured from stratospheric air samplesobtained at $41 \mathrm{~km}$. FEMS Microbiol Lett 2003;218:161-5.

Wang G, Niu S, Liu C, Wang L. Identification of dicarboxylic acidsand aldehydes of PM10 and PM2.5 aerosols in Nanjing, China.Atmos Environ 2002;36:1941-50

Wentworth SD, Cooper DG. Self-cycling fermentation of a citricacid producing strain ofCandida lipolytica. J Ferment Bioeng 1996;81:400-5.

White TJ, Bruns T, Lee S, Taylor J. Amplification and directsequencing of fungal ribosomal RNA genes for phylogenetics.In: Innis MA, Gelfand DH, Sninsky JJ, White TJ, editors. PCRProtocols: A Guide to Methods and Applications. San Diego:Academic Press; 2002. p. 315-22.

Wu Z, Blomquist G, Westermark SO, Wang XR. Application of PCRand probe hybridization techniques in detection of airbornefungal spores in environmental samples. J Environ Monit2002;4:673-8.

Yeoman MM. Metabolism of malonate by mycelial suspensions ofAspergillus niger. New Phytol 1965;64:65-79 